\title{
Comunidade virtual de práticas de formador de formadores: um convite à escrita de narrativas de experiências vividas
}

\section{The virtual community of practices for trainers' educators: an invitation to write narratives about lived experiences}

\author{
Renata Barroso de Siqueira Frauendorf* \\ Guilherme do Val Toledo Prado*
}

\begin{abstract}
RESUMO
A criação de uma comunidade virtual de práticas de formador de formadores faz parte de uma investigação narrativa de doutorado, em processo, que tem como um dos objetivos (re) colher narrativas de formador de formadores a fim de organizar uma coleção de registros que possa ser fonte de conhecimento para esses (e desses) profissionais. Os formadores, assim como professores e profissionais da educação, sempre têm boas histórias para contar, mas nem sempre as registram ou partilham. Há narrativas inspiradoras e felizes; outras inspiradoras e tristes; algumas nada inspiradoras, mas muito potentes para se refletir sobre a atuação e as condições de trabalho oferecidas a esse profissional dentro de programas de formação continuada, entre outros aspectos. Consideramos que há muito a se descobrir pela voz de formador de formadores, e que é possível ampliar o corpus de conhecimento sobre esse profissional e seu campo de atuação, uma vez que há pouca literatura sobre esse tema. Para acessar essas histórias se fez necessário criar um dispositivo que viabilizasse e mobilizasse a escrita de produções de saberes experienciais numa dimensão narrativa e formativa. Neste texto pretendemos compartilhar o processo de criação e administração de um grupo privado em rede social -
\end{abstract}

*Universidade Estadual de Campinas. Faculdade de Educação. Campinas, São Paulo, Brasil. E-mail: re.frau@hotmail.com - https://orcid.org/0000-0001-5567-3235 E-mail: toledo@unicamp.br - https://orcid.org/0000-0002-2415-8369 
no recorte de seus dois primeiros meses de funcionamento - e o que temos aprendido e refletido como investigadores narrativos a partir do movimento de elaboração e acompanhamento de postagens e reações no grupo.

Palavras-chave: Formação de formador. Narrativas. Formação continuada. Comunidade de práticas. Coletivos.

\begin{abstract}
The creation of a virtual community of practices for trainers' educators is a part of the doctorate's narrative inquiry, in process, which has its main goal in (re)gathering trainers' educators' narratives to organize a collection of records that may be a source of knowledge for these professionals. The trainers have always had good stories to tell, as well as teachers and educational professionals, but they have not always written about or shared them. There are inspiring and happy narratives; there are others that are inspiring and sad; and some which are not inspiring, but are very powerful to reflect on the performance and the working conditions which are offered to these professionals on continuing education programs, among other aspects. Since there is little literature on this subject, we consider there is still much to discover through the voice of the trainer's educator, who can contribute to broadening the corpus of knowledge about these professionals and their field of activity. To access these stories, the creation of a device was necessary to enable and mobilize the writing of experiential knowledge productions, in narrative and formative aspects. In this text, we intend to share the process of creating and managing a private group on a social network - during its first two months of operation - and what we, as narrative inquirers, have learned and reflected from the engagement of preparing and monitoring the posts and the reactions in the group.
\end{abstract}

Keywords: Education of trainers. Narratives. Continuing teacher education. Community of practice. Collectives. 


\section{Introdução}

A vida está prenhe de histórias. Ela é um enredo nascente em busca de uma parteira...

Richard Kearney

O presente estudo sobre o perfil do formador de formador faz parte da investigação de doutorado intitulada: "De estrelas à constelação: uma comunidade de práticas formativas de formador de formadores", em andamento. Uma investigação-formação inspirada na pesquisa-formação (BRAGANÇA, 2009) que assume a metodologia narrativa de pesquisa (PRADO et al., 2015) em diálogo com aportes teóricos de Walter Benjamin e autores como: IMBERNON (2011), NOVOA (2002), SENNET (2008), GALZERANI (2009), KEARNEY (2012), entre outros.

Acreditamos que esta investigação-formação poderá ampliar o corpus de conhecimento sobre esse profissional e seu campo de atuação, uma vez que observamos no Brasil um número crescente de formador de formadores em atuação, propiciando conhecimentos e saberes que possam servir de base para cursos de formação específicos para esse profissional. Partimos da ideia de que no contexto brasileiro o(a) profissional que atua em programas de formação continuada em redes públicas, em parceria público-privada, tem uma dimensão de trabalho diferente do formador de formador das universidades e nos âmbitos enunciados na literatura da área, até o momento. A ausência de cursos de formação faz com que, em geral, esses profissionais se formem em serviço e entre pares. A investigadora-formadora, uma das autoras deste artigo, e formadora de formadores nesse contexto de parcerias público-privadas, convive com muitos profissionais desse campo de atuação que revelam em seus discursos experiências pessoais e formativas intensas e singulares, dadas a conhecer, na grande maioria das vezes, via narrativa oral, raramente registradas por escrito e partilhadas entre eles. Sendo assim, entendemos ser de fundamental importância, em consonância com Prado e Soligo (2007), fomentar o registro escrito e a partilha dessas experiências. Ao narrar seu cotidiano como profissional da formação continuada, o formador de formadores partilha fragmentos de suas experiências na formação, como profissional e pessoa (NOVOA, 2002) que, ao mesmo tempo em que lhes ensina, nos ensina (leitores) a sermos formadores e pessoas melhores no contexto dos projetos formativos desenvolvidos. Os documentos desse estudo constituem-se de narrativas escritas, elaboradas 
por diferentes profissionais que atuam em distintos programas de formação continuada, para diversas instituições, produzidas em rodas de conversas, ou enviadas por correio eletrônico e/ou publicadas em um grupo privado em rede social denominado: "Comunidade de Práticas de Formador de Formadores".

O fato é que não importa o quanto as tecnologias transformem nossos modos de contar histórias, as pessoas irão sempre apreciar entrar no transe da narrativa e deixar-se conduzir através de um conto por um mestre tecelão de histórias (KEARNEY, 2012, p. 411).

É no ato de narrar que o acontecimento ganha corpo, materializa-se, porque a narrativa é sempre situada temporal e espacialmente. No contexto da formação continuada há narrativas de experiências do vivido pelo formador de formadores: divertidas, inusitadas, comuns que, por meio da interpretação e da escuta dos ditos e não ditos expressados pelos sujeitos, têm se revelado muito potentes na construção de um diálogo formativo entre pares. Aprendemos com Benjamin (1994) que a boa narrativa não é constituída por palavras eleitas, mas sim por palavras vividas; por isso nosso intuito, ao (re)colher essas narrativas, é o de compor uma coleção de histórias que possa contribuir para se pensar tanto sobre a identidade desse formador quanto sobre seu campo de atuação, seus limites e possibilidades. Aprendizagem também construída em diálogo com Sobral, Soligo e Prado (2017, p. 183) por acreditarem que:

[...] o modo narrativo é convincente porque busca verossimilhança, apresenta condições prováveis entre dois eventos, podendo até mesmo ser contraditório sem prejuízo do sentido. Além disso, se empenha em generalizar sem apagar o particular, o singular, mas transcendendo-o. $\mathrm{O}$ modo paradigmático se caracteriza por aspirar à verdade universal e o narrativo por aspirar à construção de uma coerência verossímil.

Ainda importa marcar que esta investigação-formação nasce e se alimenta de pesquisas outras produzidas no contexto do grupo de pesquisa ${ }^{1}$ do qual participamos. Este grupo se dedica desde 1996 à pesquisa sobre a formação

1 GEPEC - "Grupo de Pesquisa em Educação Continuada" da Faculdade de Educação da Universidade Estadual de Campinas(Vice coordenador atual Prof. Dr. Guilherme do Val Toledo Prado). 
permanente de professores a partir dos princípios da pesquisa-ação (GERALDI et al., 1998) e, mais recentemente, da investigação narrativa (PRADO et al., 2015). Ou seja, o presente estudo articula-se a um passado que nos foi transmitido conscientemente tanto por histórias quanto por rastros deixados em documentos, narrados por tantos pesquisadores que contribuíram com suas produções acadêmicas para compor o corpus de conhecimento desse grupo de pesquisa ao longo desses vinte e quatro anos.

Neste artigo pretendemos narrar como a criação e administração de um grupo privado em rede social - no recorte de seus dois primeiros meses de funcionamento - revelou-se um potente dispositivo para viabilizar, convidar, enfim, mobilizar a dimensão narrativa e formativa de produções de saberes experienciais (TARDIF, 2012) constituindo-se uma importante fonte de documentos interpretáveis já que a leitura das narrativas postadas na comunidade traz à superfície não somente temas, mas os sujeitos muitas vezes apagados, esquecidos, na árdua tarefa de fazer um programa de formação continuada acontecer em redes públicas de ensino brasileiras.

\section{Movimento de criação e administração da Comunidade virtual de práticas de formador de formadores}

O desejo de abrir um canal para troca de experiências entre formador de formadores fez com que fosse criado em uma rede social um grupo privado que funcionasse como uma comunidade de práticas de formador de formadores.

Para Imbernon (2011, p. 97),

Uma comunidade de práticas é um grupo constituído com o intuito de desenvolver um conhecimento especializado. $\mathrm{O}$ termo não pode ser equiparado ao que denominamos comunidade científica, já que sua finalidade é informar e comunicar experiências e compartilhar aprendizagens baseadas na reflexão (atualmente se une ao conceito de gestão do conhecimento ou prática reflexiva).

Intuímos que esse grupo poderia ser uma forma de colocar em diálogo muitos formadores que atuam em diferentes contextos e realizam diversas ações, fazendo uso de um meio que poderia potencializar a interação. Potente porque, ao aliar lampejos de memória e de experiência dos participantes, poderia, então, 
tornar-se um espaço de reflexão de saberes e fazeres desses profissionais. $\mathrm{Ou}$, em outras palavras, esse grupo poderia ser uma tentativa do "estar junto virtual", como defende Valente (2003) no artigo "Educação à distância no ensino superior: soluções e flexibilizações".

A comunidade foi criada em 10 de fevereiro de 2019 e é administrada pela autora do artigo que atua como formadora de formadores em programas de formação continuada para redes públicas de ensino. Embora continue aberta, a investigação-formação de doutorado considerará apenas as produções do ano de 2019. Atualmente é constituída por 108 membros, em sua maioria mulheres, formadoras de formadores, isto é, a profissional que atua em programas de formação continuada, no contexto de parcerias público-privadas, em escolas, centros de formação, secretarias de educação, diretorias ou regionais de ensino, responsável por desenvolver, principalmente, a formação continuada de gestores, equipes técnicas, o que faz com que tenha saberes outros relacionados ao seu fazer e ser. Isso significa que o sujeito da formação não é exclusivamente o (a) professor(a) - formador de crianças e jovens. Compreender a que profissional estamos nos referindo é fundamental para dar sentido aos registros e narrativas que aqui serão partilhadas. Sendo assim, o/a formador/a de formadores é:

... aquele [a] que traz em seu repertório um conjunto de saberes referentes à prática na instituição, consolidando uma assessoria entre pares. Cabe a este [a] profissional atender às demandas dos professores [as] e profissionais da educação de uma determinada escola, instituição educativa ou rede de ensino, para aprimorar e desenvolver processos de ensino em colaboração [...] (FRAUENDORF 2016, p. 68).

Ideia germinada, comunidade em movimento, desejo de fomentar a constituição de um coletivo, mesmo que virtual. Se considerarmos, numa linha de pensamento mais benjaminiana, que a experiência é a base do conhecimento, que a experiência se constitui coletivamente e que essa é uma forma de produção de conhecimento das sociedades, talvez comunidades de práticas com essa perspectiva possam vir a se contrapor ao movimento de enfraquecimento e desvalorização dos coletivos, gerado em decorrência da modernidade capitalista. Talvez essa comunidade virtual possa vir a se configurar em uma brecha no movimento instituído na sociedade. Uma possibilidade de brecha, que não deixa de também ser ambígua, se levarmos em conta que a rede social é uma invenção da modernidade que, em nome do "desejo" de encurtar a distância, tempo e espaço entre pessoas e mundo, conectar diferentes realidades e pensamentos, 
está por reforçar a ideia capitalista do individualismo, da vida como mercadoria, do prazer acima de tudo, da sociedade de espetáculo (DEBORD, 2003) em que todos precisam ver e ser vistos. Época de excessos de (des)informação, de impaciências; tempos que fortalecem a imagem fantasmagórica (BENJAMIN, 1994) do mundo moderno caracterizado pelo belo, ideal, feliz, imediato e prazeroso. Sentimento ambíguo porque, enquanto almejamos esse mundo encurtado de distâncias, conectado nos diferentes espaços e tempos, ainda mais em período de pandemia, rechaçamos todo o resto que vem junto!

Mesmo frente a todo esse sentimento de ambiguidade, foram nas palavras de Benjamin (1994, p. 114) que buscamos inspiração para criar este coletivo virtual, uma vez que, segundo o autor, é preciso "transmitir de boca em boca" as experiências vividas. A arte está nessa transmissão, nesse comunicar, porque os acontecimentos que não foram narrados não deixam vestígios. Portanto, o conhecimento é algo produzido quando comunicamos aos outros o processo vivido, os saberes construídos; quando intercambiamos visões, sentimentos que fazem sentido para mim na relação com o outro. De modo geral os livros e as pesquisas que tratam sobre o trabalho do formador de formadores o fazem como verdades instituídas, sendo raras as publicações que se ocupam em comunicar os saberes experienciais construídos por tantos profissionais em seu cotidiano. Nas palavras de Kearney (2012, p. 425): "a narrativa [...] é mais próxima da arte do que da ciência; ou, se preferirem, das ciências humanas do que das exatas [...]".

Para participar desse grupo privado foram convidadas algumas pessoas mais próximas ao círculo de relações da investigadora-administradora da comunidade de práticas que já atuavam como formadoras de formadores. O movimento de adesão foi muito rápido e após nove dias de criação, o grupo já continha 69 participantes, incluindo alguns profissionais indicados por esses participantes originais. Por se tratar de um grupo privado os convites para participação precisam de autorização prévia, esse cuidado reflete a preocupação em não desconfigurar a essência da comunidade de práticas garantindo a reunião apenas de formador de formadores nesse momento da investigação. Para quem chega ao espaço a comunidade de práticas é apresentada da seguinte forma:

Este é um grupo fechado que nasce pelo desejo de criar um canal para troca de experiências entre formador de formadores. Em minha trajetória como formadora de formador tenho encontrado muitas(os) formadoras(es) e elas/eles sempre têm boas histórias para contar, mas nem sempre as registram. Já ouvi histórias inspiradoras e felizes; outras inspiradoras e tristes; algumas nada inspiradoras, mas muito potentes para se refletir sobre a nossa atuação e as condições de trabalho oferecidas. Histórias 
divertidas, inusitadas, comuns... enfim, há um mundo a se descobrir pela voz dos formadores. Meu convite é a escrita de uma experiência, ou uma memória, ou um fragmento de um acontecimento, ocorrido durante um encontro de formação, preparação para o encontro, visita à escola, por exemplo... Enfim, gostaria muito de ouvir a sua história e assim organizar uma coleção de histórias de formador de formadores: se você tivesse que narrar uma experiência sua como formadora ou formador, qual seria?... Vamos juntos fortalecer esse nosso trabalho e campo de atuação na educação criando uma comunidade de práticas de formador de formadores ${ }^{2}$.

Com esse convite acolhedor e estimulador, os participantes da comunidade de práticas adentram e passam a conviver com as narrativas que ali são socializadas e, por conta da confiança constituída, podem partilhar suas práticas e vivências dentro do grupo virtual.

\section{Movimento na comunidade}

A vida é mais tempo alegre do que triste. Melhor é ser. Adélia Prado

O movimento inicial de postagens e reações foi bem mais lento do que o previsto e bem menos interativo do que supúnhamos enquanto investigadores. Talvez ainda haja uma certa resistência das formadoras em escrever, expor-se, ou talvez dificuldade, ou ainda falta de interesse, tempo... Talvez nosso olhar ainda esteja aprisionado na falsa ideia de sucesso relacionada às ações a curto prazo, ao imediatismo de respostas, como nos é vendido no novo capitalismo (SENNET, 2008). O problema está neles ou em algo que não enxergamos?

Na plataforma digital escolhida para criação da comunidade há seis diferentes tipos de reação possíveis sendo: curtir amei, haha, uau, triste e grr. Além de ser possível apenas visualizar a postagem ou comentá-la. Nos

2 Esse texto foi adaptado da carta convite para a participação na pesquisa. Todas as narrativas aqui partilhadas foram autorizadas por seus autores, bem como o projeto aprovado no Comitê de Ética e Pesquisa sob o CAAE 09711519.1.0000.8142 no ano de 2019. 
comentários é também possível reagir e responder. Nossa intenção nesta publicação não é a de aprofundar sobre esse assunto, mas tratar brevemente sobre os sentidos e significados atribuídos às reações ou não reações às postagens e como isso foi impulsionando, constituindo e mesmo direcionando (ou aprisionando) as escolhas e caminhos trilhados no fomento à comunidade. Sentidos que também foram sendo alargados e ressignificados ao longo de todo o processo vivido como, por exemplo, a relação construída com a ausência de resposta ou "silêncio", como nomeamos frente a algumas postagens.

O silêncio, no sentido de calar-se, é também uma forma de manifestação, porém não controlável por algoritmos. Sentidos e significados para os silêncios se intuem, porque não há um único sentido e significado possível de ser atribuído.

O silêncio não está disponível à visibilidade, não é diretamente observável. Ele passa pelas palavras. Não dura. Só é possível vislumbrá-lo de modo fugaz. Ele escorre por entre a trama das falas (ORLANDI, 2007, p. 32).

Fomos aprendendo que o fato de visualizar ou "curtir" uma postagem pode significar uma aproximação ainda que superficial ao conteúdo, porém não é necessariamente indicação de leitura do conteúdo. Já reações como "amei", "triste" e "uau" pressupõem um tipo de interação um pouco mais específica com a postagem o que provavelmente teria demandado uma leitura, pois são reações que idealmente demonstram uma forte aprovação, empatia com a situação/publicação ou mesmo interesse ou ainda surpresa (SOUZA, 2016) . Outra forma de reação possível são os comentários dos leitores exigindo do autor não só a leitura do conteúdo postado, a reação imediata, mas também a produção de um texto em que o leitor/autor expressa a opinião sobre o que leu, assistiu ou ouviu, muito embora o discurso tenda a ser menos formal e os textos de pequena a média extensão.

A comunidade de práticas recebeu, inicialmente, duas postagens espontâneas de participantes e uma da administradora. Porém o máximo de reações, nas primeiras semanas, foram apenas algumas "curtidas" e visualizações.

Diante dessa primeira constatação, a investigadora-administradora do grupo fez a postagem de uma narrativa que fez parte de sua dissertação de mestrado, lançando junto a seguinte provocação: "o formador de formador, o que já se sabe sobre esse profissional?" Consideramos que poderia ser uma provocação potente e outra forma de iniciar o diálogo, já que a comunidade é formada por 
diferentes formadoras que atuam em diferentes instâncias e contextos, unido ainda à ideia da dificuldade de definição do papel de um formador de formador com a qual frequentemente nos deparamos na literatura sobre a temática. Essa indefinição sobre o papel desse profissional foi comunicada aos participantes por meio da seguinte narrativa:

O formador de formador - o que já se sabe sobre esse profissional?

Essa pergunta durante o processo de auto investigação realizado no mestrado me angustiou bastante porque atinei que essa definição não era precisa e que havia pouca literatura sobre esse tema. Isto gerou, naquele momento, uma crise de identidade profissional, por perceber que não era ainda uma atividade socialmente reconhecida [...] penso que toda essa confusão e falta de clareza vêm coladas a transformações sofridas pela concepção de formação continuada, e as diferentes denominações que esse profissional recebe: assessor, formador, consultor, supervisor, professor-formador, orientador. Claro que não se trata de uma simples variação de nomes, mas de ações bem específicas que mudam conforme o programa, o contexto, a condição de produção, o processo de formação vivido pelos sujeitos da formação, entre outras variáveis. Assim, a partir das produções escritas que encontrei, organizei um quadro[...]. Na época lembro que me ajudou muito a me encontrar, mesmo que parcialmente... (Registro feito em Comunidade de Práticas de Formador de formadores publicado em 19/02/2019).

Essa postagem-provocação gerou 58 visualizações, dois comentários de participantes, uma réplica - da administradora, uma tréplica e 4 curtidas. Será que a consigna/comanda não havia sido convidativa ou provocadora o suficiente? Novamente o sentimento de ambiguidade surge!

Diante do silêncio e/ou pouca interação, a investigadora-administradora do grupo escreveu um novo "convitintimação" ou convite/intimação de forma a recuperar o objetivo da comunidade: ser um espaço de partilha de experiências, como pode ser visto no fragmento a seguir:

Olá queridos formadores e formadoras desta comunidade, nosso espaço de partilha de experiências está aberto e aguardando contribuições! Todos nós temos uma vida intensa de atribuições como: preparação de pauta, escrita de devolutivas, viagens, realização de encontros, acompanhamentos às 
escolas, organização de ppt, seleção de textos para estudo e/ou para leitura literária, entre outras tantas coisas, não, é? Então, que tal contar para nós um pouquinho do seu cotidiano como formador(a) de formador(a)! (Registro feito em Comunidade de Práticas de Formador de formadores publicado em 27/02/2019).

A postagem foi visualizada por 55 membros, recebeu 8 "curtidas" e 1 comentário/pergunta: Onde postar? que foi respondido diretamente à participante, orientando-a como fazer.

Ainda como resposta a essa provocação a comunidade recebeu a postagem de uma narrativa de Cora $^{4}$ em que ela conta sobre a sua experiência durante 17 anos como coordenadora pedagógica em uma escola e a rotina de escrever devolutivas aos registros das professoras.

Fui coordenadora pedagógica de escola municipal por mais de 17 anos, em minha rotina analisava as atividades dos cadernos dos alunos, uma série por semana. Após observar cadernos de alunos médios, anotava uma devolutiva para a professora. Nessa devolutiva, em caderno próprio, anotava sugestões de atividades, questionava as cópias excessivas em cadernos de quarto e quintos anos, por exemplo, etc. Essas devolutivas eram formativas na medida em que conversava com as professoras no momento de entregá-las (Registro feito em Comunidade de Práticas de Formador de formadores publicado em 27/02/2019).

A postagem recebeu como reação 8 "curtidas" e foi visualizada por 38 membros. Quatro dias depois do "convitintimação", também se sentindo talvez provocada, Melissa - coordenadora pedagógica da rede pública e formadora de formadores em programa de formação continuada do governo federal - postou a sua narrativa: Uma escola sem livros. Essa postagem gerou 10 reações sendo 9 "curtidas" e 1 "amei" - da administradora do grupo. Foi visualizada por 43 membros.

4 Os nomes utilizados são fictícios, alguns escolhidos pelas próprias autoras como Melissa, outros inspirados em nomes de autoras da literatura como Cora, Hilda. A razão para essa inspiração é o nosso gosto por ler e por compreender que a formação do leitor está entre um dos compromissos do formador, isto é, despertar no outro o desejo de ler e ampliar seus repertórios e experiências de leitura. 
Uma escola sem livros

Desenvolvendo um trabalho de formação em outras escolas, não na que atuo como Professora Coordenadora vivenciei um momento que venho compartilhar neste grupo, através desta narrativa.

No encontro planejado para a semana, a proposta era estudar com os professores alfabetizadores, leitura. $\mathrm{O}$ objetivo era dar luz às concepções de leitura subjacentes das práticas pedagógicas, e juntos pensarmos como a escola pode se reinventar, partindo da análise dos seus indicadores internos e externos, para então, realizar um Plano de Ação que apresente uma proposta de intervenção por parte da equipe escolar, em especial dos professores e da professora coordenadora, com o intuito de fazer os alunos avançarem na construção dos conhecimentos esperados para o ano, principalmente com relação à leitura. [...]

Pauta formativa pronta. Fiz uma reunião prévia com a professora coordenadora, visando traçar, juntas, um caminho para a proposta de uma ação na escola em relação à leitura. Tal foi a minha surpresa, quando ela me disse que a escola não possuía acervo literário. Nenhum livro, nada! Fiquei paralisada e pensando "como pode uma escola não ter livros?" [...] (Registro feito em Comunidade de Práticasde Formador de formadores publicado em 28/02/2019).

Recebeu também o comentário da administradora na perspectiva de ampliar o diálogo. Este comentário gerou 2 reações: 1 "curtida" e 1 "amei" - sendo esse da própria autora do comentário.

Acho essa sua narrativa tão forte, Melissa! Ela me faz pensar nas tantas vezes que fiz todo um planejamento partindo de algo que achava ser um fato e no momento real me deparar com outra realidade. Penso que aprender a lidar com isso e passar a considerá-la nos momentos de planejar, um saber de formador.

Nesse movimento compreendemos que tínhamos muito a aprender, pois inicialmente nos prendíamos, enquanto "leitores" do movimento da comunidade, na ausência de reações e à falta de interação. Ficamos aprisionados à imagem empobrecida do sentido do silêncio, imagem socialmente construída como algo desvalorizado, relacionado ao descaso, desinteresse, como se o valor da ação de narrar pudesse ser medido pela quantidade de barulho desordenado, ou por burburinho de reações. 
Ao refletirmos e recuperarmos esse percurso, conseguimos perceber que a provocação gerou um movimento reflexivo, encorajou duas participantes a escreverem, gerou reações diferentes, gerou ditos e não ditos. Uma reflexão que de certa forma nos encorajava a não abandonar a proposta da Comunidade de Práticas até se seguir um novo e longo silêncio.

\section{Silêncios... outros}

...todo o silêncio é música em estado de gravidez.

Mia Couto

Quase um mês se passou sem que ninguém postasse, comentasse ou mesmo reagisse a alguma postagem. Foi também um mês puxado de trabalho para a investigadora-administradora da comunidade, com muitas viagens, o que a fez considerar o quanto isso é rotineiro na vida da formadora de formadores, principalmente quando não pertence à rede de ensino de atuação, fazendo com que viaje e circule por diferentes lugares, num curto intervalo de tempo. Nesse rápido exercício de reflexão pudemos nos colocar no lugar da formadora que participa da comunidade de práticas e conjecturamos que: "se esperávamos que algo fosse publicado na comunidade de práticas após uma formação, porque nós não havíamos dado o primeiro passo nesse sentido? " Diante dessa autoprovocação/constatação, a investigadora-administradora fez uma publicação em tom de desabafo diante do que havia observado em um certo acontecimento.

Estive fora vários dias fazendo formação. Fui a Bahia, passei por SP e dei uma chegada em Sergipe, isso em duas semanas! Apesar do cansaço e da vontade de voltar para casa, penso que essa é uma das minhas grandes alegrias como formadora. A possibilidade de circular pelo Brasil, conhecer diferentes realidades, relacionar-me com pessoas distintas que, ao revelar diferentes experiências, contam as dores e os encantos do dia a dia da escola. Por outro lado, nesse trajeto me deparo, muitas vezes, com situações tão desafiadoras e assustadoras que me sinto tão impotente e frágil que preciso encontrar coragem para seguir adiante. $\mathrm{E}$ a coragem vem do desejo de transformar o espaço da escola como um lugar de vida e aprendizagem e não reprodutor de exclusão (Registro feito em Comunidade de Práticas de Formador de formadores publicado em 21/03/2019). 
Essa postagem gerou 24 reações: 18 "curtidas" e 6 "amei”, 77 visualizações e 7 comentários, sendo 4 compostos por texto verbal e 3 como resposta de aprovação/ aceitação com uso de emoji (EMOJI, 2020) ${ }^{5}$.

Hilda: Formar, formando-se e transformando-se para a construção desse espaço de reconstrução desse lugar de vida! Um presente, ganho, não. Conquistado! Grande e generosa parceria!

Adélia: É remar contra a maré parceira. Sobre remar contra a maré já aprendemos um pouco, não é?

Reflexões que mobilizaram o desejo da investigadora-administradora se posicionar novamente, e reagir de forma afetiva:

Com certeza, Adélia! Remar contra muitas marés, às vezes num mesmo espaço de tempo e lugar. E a gente sai com coração apertado vendo o tanto que precisa ser feito. Por isso trabalhar em parceria é o que pode dar sentido e nos fortalecer!

O diálogo ainda foi ampliado e Elena se posicionou frente às publicações escrevendo:

Eu também estive imersa em uma formação na semana passada e na sexta pensava, apesar de muito cansada e querendo voltar para casa, o quanto amo tudo isso! Conhecer as pessoas, aprender com elas quando pensamos e refletimos sobre os conteúdos da formação é algo incrível para mim! Sempre vou às escolas para me aproximar das realidades locais e manter minha conexão do que porque estamos ali, a razão de todo nosso trabalho: a garantia das aprendizagens das crianças! São elas a razão de tudo.

5 Ideogramas e smiles usados em mensagens eletrônicas e páginas web. Eles existem em diversos gêneros, incluindo: expressões faciais, objetos, lugares, animais e tipos de clima. 
Nesses lampejos das experiências vividas encontramos os vestígios do princípio de uma comunidade de aprendizagem (WENGER, 2001) cuja relevância está na possibilidade de troca dos saberes experenciáveis produzidos no calor da ação e da reflexão. A postagem da investigadora-administradora provocou uma série de reações que ainda não tínhamos observado como, por exemplo, 6 "amei” de diferentes participantes do grupo. Então nos perguntamos: teria a narrativa as provocado a pensar em coisas que ainda não haviam pensado? A exposição do sentimento, do humano, de uma racionalidade mais estética e ética do que técnica, via texto da investigadora-administradora materializou uma experiência vivida por ela e talvez por outros tantos, e esse encontro possibilitou que a palavra circulasse, sem controle, sem limites. Entendemos que a narrativa singular abriu a brecha para que algumas participantes sentissem o desejo de escrever, compartilhar seus sentimentos, partilhar suas impressões em diferentes tempos, espaços e contextos.

Um dos elementos que constitui uma Comunidade de Práticas é o fato de que as pessoas participam ou, nesse caso, partilham ações que vão sendo significadas e ressignificadas a partir do diálogo com o outro, parceiro de trabalho (WENGER, 2001). Sem dúvida, quando a investigadora-administradora narra seu cotidiano de formadora de formadores e, ao rememorar o acontecido, explicita os sentimentos ambíguos envolvidos em sua prática: frustrada por se perceber frágil e com limites - imagem bem distinta da que se idealiza do formador como o sujeito que tem respostas para tudo, aquele que será o responsável por trazer o avanço, o que há de mais moderno em termos de educação - ela abre uma possibilidade de comunicação mais profunda, sensível e humana com outras formadoras.

Segundo Kearney (2012, p. 419, grifo nosso) "é precisamente este jogo de diferença e identidade - experimentar a si próprio como outro e o outro como a si próprio - que provoca uma reversão de nossa atitude natural diante das coisas e nos abre novas maneiras de ver e ser."

$\mathrm{Na}$ tessitura dos comentários e reações acontecem encontros, uma aproximação com o outro, há mais que o sentimento de empatia porque há troca, há tensão, há correspondência na experiência (GALZERANI, 2009).

\section{Noite Estrelada}

Após 77 dias de criação do espaço virtual para partilha de experiências vividas por formadoras de formadores e com 78 participantes a investigadora- 
administradora mudou a imagem de capa do grupo e, embora o movimento da comunidade não correspondesse ao que havia imaginado inicialmente (várias postagens de narrativas dos participantes, grande interação via comentários às publicações), havia o que comemorar e marcar conforme é possível observar na postagem a seguir. Elegeu como capa a obra "Noite Estrelada" de Van Gogh e deixou a seguinte mensagem ao grupo:

Olá membros dessa comunidade! Já faz 77 dias que essa comunidade foi criada, e estamos atualmente com 78 participantes. Um grupo constituído por formador de formadores que, por meio da escrita de algumas experiências partilhadas, tem me ajudado a refletir sobre muitas coisas relacionadas a nossas ações, desafios, limites e alegrias[...] Para Walter Benjamin aí está o poder das narrativas que ao serem compartilhadas no grupo ao qual pertenço transforma uma simples vivência em experiência. E é essa a finalidade de uma comunidade de práticas: informar, comunicar experiências e compartilhar aprendizagens baseadas na reflexão. Interessante pensar nisso! [...]

E termino com um convite para que você passeie, despretensiosamente, sem rumo determinado, deixe-se perder no labirinto dos comentários, postagens desta comunidade e acaso se depare com algum escrito, imagem, comentário que de alguma forma te provoque, ou te atravesse de algum modo, deixe uma marca que por ali passou. Que tal?

Era preciso pensar e o convite para passear pela comunidade era uma oportunidade de parar o tempo, de interromper o pensamento e sair do lugar comum! Rememorar o percurso vivido após dois meses e meio de criação foi extremante importante para a administradora da comunidade e também para nós, investigadores narrativos, a fim de alargarmos a nossa compreensão sobre o real papel desse dispositivo. Ao passear pela comunidade despretensiosamente, tal como um flâneur (BENJAMIN, 2018) pudemos ver um movimento do grupo que não estava sendo reconhecido. Pudemos ver com um "olho que realmente enxergue" assim como Hoffmann nos convida em vários trechos de sua narrativa autobiográfica "A janela da esquina de meu primo" (Edição da Editora Cosac Naify de 2010). Era preciso reconhecer que havia o que comemorar, porque havia diálogos, havia várias formas de reações das participantes, assim como muitas visualizações de diferentes postagens e havia silêncios, silêncios compreendidos como também uma forma de se manifestar e que, embora ainda gerem certo desconforto, passaram a ser mais reconhecidos no contexto da investigação. 
Esse caminhar despretensioso pelas "vitrines da comunidade", num espaço similar às Passagens parisienses do século XIX - tão bem ilustradas por palavras e imagens banhadas por nossos diálogos com leituras benjaminianas - em que a estrutura, os ferros e vidros são semelhantes à ideia de conexão, redes sociais e murais, muito nos ensinou como investigadores(as)/formadores(as). Era essa a relação de sentido que precisávamos construir com a comunidade de práticas. Todo esse movimento nos fez despertar, acordar do sonho em que é preciso ter um número grande de curtidas, visualizações, comentários, para significar que algo é eficiente ou tem sucesso. Havíamos sido capturados pelo movimento da modernidade capitalista, estávamos reféns de uma sociedade que aplaude o instantâneo, o imediato, e talvez por isso sentindo-nos incomodados com o que julgávamos o "fracasso da comunidade".

\section{O que temos aprendido com a comunidade?}

O livro pode valer pelo muito que nele não deveu caber. Guimarães Rosa

Certamente a Comunidade virtual de práticas de formador de formadores não tem funcionado como intuímos que seria. De lugar de circulação intensa de narrativas escritas e imagens de situações do cotidiano de formadores de diferentes contextos, ela passou a ser o lugar do pensar, de reflexão e aprendizagem do(a) investigador/a entremeado pelos silêncios, pelas ausências, por presenças, por distintas reações de participantes, por escritas de comentários. Não consideramos que isso desmereça o propósito inicial ou se configure apenas numa "evidência" de um caminho diferente das expectativas traçadas inicialmente. Entendemos que a história até aqui narrada revela uma trajetória que foi sendo construída e modificada à medida que o dispositivo - nesse caso a comunidade de práticas - foi sendo colocado em uso, à medida que diferentes pessoas passaram a se relacionar das mais diversas formas, e, principalmente, à medida que possibilidades e sentidos outros puderam ser traçados por nós e para além de nós. Todo esse fazer tem contribuído intensamente para compreender tanto o que se relaciona à temática do formador de formador como também à do investigador(a) narrativo. 
Ao escrever sobre o que the acontece, sobre o que lhe toca, sobre suas experiências, o educador/pesquisador vai construindo uma consciência do que se passa com ele e, assim como o fotógrafo toma decisões sobre o que focar, tipo de luz necessária, melhor ângulo, o que incluir e o que excluir na cena. Ele vai realizando escolhas ao registrar, e será justamente neste processo de narrar, das reflexões suscitadas, aliado a explicitação do porquê de ter selecionado determinado tema, ou experiência, que poderá tornar o texto um material precioso para ser analisado e compreendido (FRAUENDORF et al., 2016, p. 354).

Nas palavras de Imbernon (2011, p. 59) encontramos alimento, inspiração e alento para continuar o movimento da comunidade pensando na potência que ela se constitui tanto relacionada à formação continuada como à investigação:

Ninguém aprende a dirigir ou a nadar unicamente mediante apresentações de power point. Ninguém aprende a refletir ou a projetar teoricamente. Muitas das coisas em formação permanente não se ensinam, se aprendem. Situemos os professores, não tanto em uma atitude de que lhes ensinemos, mas sim em situações de aprendizagem. Para isso deveremos mais que ensinar ou formar, criar situações e espaços de reflexão e formação.

Elencamos aqui algumas reflexões, iniciais ainda, do que relacionar-se com esses fragmentos de experiências vividas têm nos possibilitado de aprendizagens.

\section{Estamos aprendendo:}

...a olhar para as brechas e compreender o movimento que a comunidade vai desvelando.

.... repensar a ideia de que eficiência, sucesso, está relacionada à quantidade de curtidas e comentários de uma postagem.

...a despertar o desejo pelo diálogo e interação - seja via escrita, imagem. ...a entender que a reverberação do que circula na comunidade pode ir além do que é visível e explicitado pelas reações dos participantes e que não há controle. 
...a compreender que a comunidade é um coletivo que tem um ritmo, movimento próprio.

...a compreender que talvez a formadora de formador ainda não tenha o hábito de partilhar suas experiências seja num registro escrito ou imagem.

...a enxergar que para alguns há uma ideia de que para escrever é preciso "estar certo", ter uma prática exemplar, e por isso para esses sujeitos se torna um desafio se arriscar na escrita partilhável de suas experiências.

...a compreender o dispositivo de escrita de narrativas à medida que vai se revelando para nós.

...a compreender que "eu" sou um sujeito mergulhado na cultura e por isso toda a minha percepção e conhecimento estão sendo produzidos social e historicamente.

Em outras palavras, podemos dizer que estamos vivenciando a ideia de que:

O trabalho com a narrativa de vida coloca o pesquisador diante de uma epistemologia do diálogo, da partilha, da empatia entre dois sujeitos que aprendem, que formam em comunhão, assim, uma nova epistemologia de investigação e de formação (BRAGANÇA, 2009, p. 37).

Como pesquisadores, buscamos narrar a nossa experiência em relação à experiência de tantos outros que, de forma explícita ou implícita, circulam e constroem este coletivo, ainda que virtualmente.

\section{REFERÊNCIAS}

BENJAMIN, Walter. Passagens. Belo Horizonte: Editora UFMG, 2018. v. 1.

BENJAMIN, Walter. Magia e técnica, arte e política: ensaios sobre literatura e história da cultura. São Paulo: Brasiliense, 1994.

BRAGANÇA, Inês Ferreira de Souza. Pesquisa-formação e histórias de vida de professoras brasileiras e portuguesas: reflexões sobre tessituras teórico-metodológicas. Revista@mbienteeducação, São Paulo, v. 2, n. 2, p. 37-48, ago./dez. 2009.

DEBORD, Guy. A sociedade do espetáculo. Tradução de www.terravista.pt/ IlhadoMel/1540. eBooksBrasil.com, 2003. Disponível em: https://www.marxists.org/ portugues/debord/1967/11/sociedade.pdf. Acesso em: 29 jul. 2020. 
EMOJI. WIKIPÉDIA, a enciclopédia livre. Flórida: Wikimedia Foundation, 2020. Disponível em: https://pt.wikipedia.org/w/index.php?title=Emoji\&oldid=59270832. Acesso em: 29 jul. 2020.

FRAUENDORF, Renata Barroso de Siqueira. A voz de uma professora - formadora que se inventa e reinventa a partir da/com/na escola. 2016. Dissertação (Mestrado em Educação) - Universidade Estadual de Campinas, Campinas, 2016.

FRAUENDORF, Renata Barroso de Siqueira et al. Mais além de uma história: a narrativa como possibilidade de auto formação. Revista de Educação PUC-Campinas, Campinas, v. 21, n. 3, p. 351-361, dez. 2016. ISSN 2318-0870. Disponível em: http://periodicos.puccampinas.edu.br/seer/index.php/reveducacao/article/view/2908. Acesso em: 29 jul. 2020.

GALZERANI, Maria Carolina Bovério. DEPRAC - Aula : Memória e História em Walter Benjamin.Campinas: FE-UNICAMP, 2009. 1 vídeo (2h 36m). Publicado pelo Canal Materiais Educacionais produzidos na FE - UNICAMP. Disponível em: https:// www.youtube.com/watch?v=RfmXD6gMkK8. Acesso em: jul. 2020.

GERALDI, Corinta Maria Grisolia; FIORENTINI, Dario; PEREIRA, Elisabeth Monteiro de Aguiar (org.). Cartografias do trabalho docente: professor(a)-pesquisador(a). Campinas, SP: Mercado de Letras, 1998.

HOFFMANN, Ernest Theodor Amadeu. A janela da esquina de meu primo. Tradução de Maria Aparecida Barbosa. Posfácio de Marcus Mazzari. São Paulo: Cosac Naify, 2010.

IMBERNON, Francisco. Escola, formação de professores e qualidade do ensino. Tradução de Ricardo Pérez Banega. Pinhais: Melo, 2011.

KEARNEY, Richard. Narrativa. Educ. Real, Porto Alegre, v. 37, n. 2, p. 409-438, maio/ ago. 2012. Disponível em: http://www.ufrgs.br/edu_realidade. Acesso em: jul. 2020.

NOVOA, Antonio. Formação de professores e trabalho pedagógico. Lisboa: Educa, 2002.

ORLANDI, Eni Puccinelli. As formas do silêncio: no movimento dos sentidos. 6. ed. Campinas, SP: Editora da Unicamp, 2007.

PRADO, Guilherme do Val Toledo, SOLIGO, Rosaura Angélica. Porque escrever é fazer história: revelações, subversões, superações. Campinas: Átomo e Alínea, 2007.

PRADO, Guilherme do Val Toledo et al. Metodologia Narrativa de Pesquisa em Educação: uma perspectiva bakhtiniana. São Carlos: Pedro \& Joao Editores, 2015.

SENNETT, Richard. A corrosão do caráter: consequências pessoais do trabalho no novo capitalismo. Tradução de Marcos Santarrita. 13. ed. Rio de Janeiro: Record, 2008.

SOBRAL, Adair; SOLIGO, Rosaura Angélica; PRADO, Guilherme do Val Toledo. $A$ subjetividade autoral em textos acadêmicos: algumas considerações. Nonada: Letras em Revista, Porto Alegre, n. 28, v. 1, p. 174-193, maio de 2017. 
SOUZA, Elson de. Globo. com. Techtudo. Grr, Uau, Haha... Entenda significados dos botões do Facebook Reactions. Disponível em: https://www.techtudo.com.br/dicas-etutoriais/noticia/2016/02/grr-uau-haha-entenda-significados-dos-botoes-do-facebookreactions.html. S.l., 2016. Acesso em: 26 jul. 2020

TARDIF, Maurice. Saberes docentes e formação profissional. Petrópolis: Vozes, 2002.

VALENTE, José Armando. Educação a distância no ensino superior: soluções e flexibilizações. Interface - Comunic, Saúde, Educ., Botucatu, v. 7, n. 12, p. 139-142, fev. 2003.

WENGER, Etienne. Comunidades de práctica: aprendizaje, significado e identidade. Barcelona: Paidós, 2001.

Texto recebido em 30/07/2020.

Texto aprovado em $08 / 10 / 2020$. 